\title{
Transition and Translation of Free Indirect Discourse in Chinese Literature
}

\author{
Yixin Liu \\ Department of Asian Studies, The University of Edinburgh, UK
}

\begin{abstract}
Free indirect discourse (FID) is a discourse presentation pattern of third-person narration, and it is often employed as a common narrative strategy to present characters' consciousness in literary works. Given its ambiguous link with both the narrator's and character's discourse, we may feel confused about how to distinguish FID from other discourse when reading a text. After introducing the basic definition of this notion, this paper will interpret several signals which can help to distinguish FID passages in the text. Most importantly, this paper will look at how FID passages in Western literary works were translated into Chinese in early works, and then explore the development of FID in early Chinese fiction, investigating the transition of FID in Chinese.
\end{abstract}

Index Terms - free indirect discourse, stream of consciousness, interior monologue, narrative discourse, Chinese literature

\section{INTRODUCTION}

Free indirect discourse (Hereafter: FID) is a discourse presentation mode of third-person narration to represent a character's speech or thoughts. The relevant studies in early times were mainly written in French, in German or in English. In Chinese academia, it has not been paid much attention.

As a common narrative strategy to present characters' consciousness, FID creates an appropriate space for the complicated interchange between narrator and character, which evokes the struggle in terms of who controls the utterance in the text. Given its ambiguous link with both the narrator's and character's discourse, we may feel confused about how to distinguish FID from other discourse when reading a text. There are several phenomena which can help to distinguish FID passages from the surrounding text in the English text. The general grammatical characteristics of FID include, like, the third-person system in third-person narrative, the lack of the introductory expression phrases, the past tense and so forth. It will be interpreted in detail later in this paper.

The appearance of FID as an independent literary technique in Chinese fiction is quite early, and it can be traced even further back than the notion of stream of consciousness. Some literary works written before the Republican era have been studied with a view to narrative method.

Given its complex relation with the concepts of interior monologue and stream of consciousness, this paper will firstly explain the relationship between the three concepts. Then, this paper will introduce the basic definition of the notion of FID, and interpret several signals which can help to distinguish FID passages in the text. Moreover, this study will explore the development of FID in early Chinese fiction, and it will look at how FID passages in Western literary works were translated into Chinese in early works, thereby investigating the transition of FID in Chinese.

Although some of the previous studies reveal that FID was borrowed from western fiction since the appearance of Chinese translations of some western fiction in nineteenth century, it is convincing that actually this "new" narrative technique was not totally introduced from western fiction. During the May Fourth era, diversified narrative techniques greatly developed in Chinese fiction, and FID began to frequently appear in the writings.

\section{The CONCEPT OF FreE INDIRECT Discourse}

\section{A. The Relationship between Free Indirect Discourse, Stream of Consciousness and Interior Monologue}

Interior monologue (Hereafter: IM) is a common technique to present stream of consciousness (Hereafter: SOC) in literary works. Some scholars think that it includes direct IM and indirect IM. Direct IM is normally used most extensively, which can be presented through two kinds of discourse forms: direct discourse (Hereafter: DD) and free direct discourse (Hereafter: FDD); indirect IM is actually correlated with indirect discourse (Hereafter: ID) and free indirect discourse (FID). By contrast, some other scholars regard FID as an independent notion.

Regardless of that, overall, to present SOC in literary works, the most common discourse presentations used are FDD and FID. As the Chinese scholar Shen Dan (1991) argues, these two forms are the most appropriate to reveal SOC in fiction. In this sense, we can say that IM and SOC partly overlap (as below): 


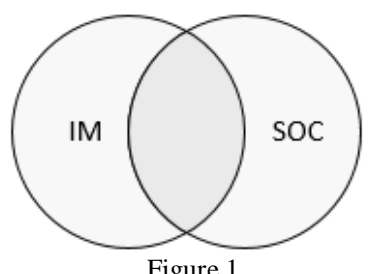

In Figure 1, interior monologue includes direct interior monologue and indirect interior monologue. Direct interior monologue can be presented through two kinds of discourse forms: direct discourse and free direct discourse; indirect interior monologue is usually correlated with free indirect discourse. In stream-of-consciousness literature, the most common discourse presentations are free direct discourse and free indirect discourse (the overlapping part).

Given that FID does not appear as frequently as DD or ID in literary works and that it was not until recent decades that FID was widely introduced in Anglo-American literary criticism, the concept of FID was often ignored by scholars (Hagenaar, 1992). However, due to its special function constructed in SOC techniques, this study will separate it from the section of IM and analyse it in detail next.

\section{B. Definition of Free Indirect Discourse}

Free indirect discourse (FID) is a peculiar style of third-person narration to represent a character's speech or thoughts. The relevant studies in early times were mainly written in French and in German, and in these languages FID was designated as style indirect libre and erlebte Rede (Hernadi, 1972; Cohn, 1978). ${ }^{1}$ In Chinese academia, it has not been paid much attention.

For example, the FID is used heavily throughout Mrs. Dalloway by Virginia Woolf (Woolf, 1925). Often it is not exactly clear through whom the reader experiences the story, the characters or the narrator. Meanwhile, the usage of FID may let the reader form his/her own interpretation of the novel, because we can find that FID is more like a dual voice, lying somewhere in between DD and ID, and sometimes it is difficult for readers to identify FID in the texts. As a mix of DD and ID, FID is always in a "sort of halfway house position, not claiming to be the reproduction of the original speech, but at the same time being more than a mere indirect rendering of the original" (Leech and Short, 2007, p.57). Thereby, it becomes important for us to first determine how FID is established as well as how it differs from other relevant discourse modes, in particular, DD and ID. Many scholars remark that FID is generally defined in opposition to both DD and ID, although FID takes features form both of them (Leech and Short, 2007; Shen, 1991).

One characteristic that distinguishes it from normal DD or ID is the lack of introductory phrases such as "he/she said" or "he/she thought", so it may be more direct to convey the character's words than in DD and ID. In this way, however, the reader possibly would feel confused about who exactly is speaking, the character, or the narrator, because there would appear an overlap of the character's and the narrator's voice, thereby further resulting in a combination of perspectives as well as a sort of polyphonic effect. Therefore, FID is also described as a "technique of presenting a character's voice partly mediated by the voice of the author" (Stevenson, 2014, p.34), or, as Gérard Genette puts it, "the narrator takes on the speech of the character, or, if one prefers, the character speaks through the voice of the narrator, and the two instances are then merged" (Genette, 1980, p.174). Furthermore, Genette's discussion in the section "narration of words" of the chapter on "Mood" clearly points out the twofold ambiguity with the usage of FID in texts (Genette, 1980, p.172). First, it would produce a confusion between uttered speech and inner speech. In other words, it may be unclear whether the words in FID are spoken by the character, or just the thoughts of his/her own. Genette exemplified his point with Marcel's statement from Sodome et Gomorrhe, "I went to find my mother: it was absolutely necessary that I marry Albertine" (Genette, 1980, p.172), through which we may question whether it is the thought Marcel has or the words that he addresses to his mother. Second, there exists confusion between the speech, no matter the uttered or inner ones, of the character and that of the narrator, that is, the ambiguity of whom contributes the discourse. Taking Flaubert as an example, Genette remarks that the advantage he derived from this kind of ambiguity "permits him to make his own language speak this both loathsome and fascinating idiom of the 'other' without being wholly compromised or wholly innocent" (Genette, 1980, p.172).

Apart from Genette, many other scholars note this sort of ambiguity associated with FID. For example, Paul Hernadi described this kind of effect as "dual perspective" in his article and he pointed out that "these dual modes of discourse may consist of seemingly authorial statements, yet they clearly evoke a character's sensory or mental vision, sometimes even stylistic peculiarities of his speech" (Hernadi, 1972, p. 41). In this article, Hernadi suggested FID as "substitutionary narration", because the narrator "substitutes his words for a character's speech, thought, sensory perception". From the point of view of grammar, Hernadi described this type of literary discourse as "an elliptical form of indirect quotation" (Hernadi, 1972, p.41). Ohmann described it as "double vision", in which "the sense of the narrator peering into the character's mind and scrupulously reporting its contents" (Ohmann, 1964, p.436).

\footnotetext{
${ }^{1}$ In 1912, the Swiss linguist Charles Bally identified this kind of narrative style as style indirect libre, while in German literature, this style had been known as erlebte Rede (experienced speech). It should be noted that since the earliest sighting of FID from Adolph Tobler in 1887, not only its definition, nature and function, but also the name of this type of discourse has not been completely come to an agreement, such as the narrated monologue, represented speech, the quasi-direct discourse, pseudo-objective and so forth.
} 


\section{Signals to Recognise Free Indirect Discourse in the Text}

Given its ambiguous link with both the narrator's and character's discourse, we may feel confused about how to distinguish FID from other discourse when reading a text. There are several phenomena which can help to distinguish FID passages from the surrounding text. The general grammatical characteristics of FID have been seen, which mainly include, like, the third-person system in third-person narrative, the lack of the introductory expression phrases, the past tense and so forth. It will be interpreted in detail below.

In terms of specific distinctive features of FID passage, many scholars have investigated them, among whom the Czech literary theorist Lubomír Doležel provides a relatively complete guide for this category. This classification is mainly based on its mixed structure as regards the features that distinguish narrator's discourse from character's discourse. It should be noted that this classification is mainly used for the study of Czech literature (Doležel, 1973). In addition, Ronald Lethcoe provides an extensive classification which applies to the representation of speech exclusively. It should be noted that Lethcoe argues that most features could be applied in different languages rather than a certain one (Lethcoe, 1969). Similarly, Rimmon-Kenan had a classification based on the comparison with DD and ID (Rimmon-Kenan, 1983). Moreover, Brian McHale and Rimmon-Kenan did a study about classification as well. McHale mainly gave a classification of data from various sources (McHale, 1978). So, the following interpretation will mainly be a synthesis of the general accounts by these scholars.

Overall, in terms of the system of the grammatical person, FID concurs completely with narrator's discourse.

In most cases, FID appears in third-person narration, in which it mainly employs the third-person system. In other words, the reference to speaker, hearer and referent is expressed by third-person verb forms as well as personal and possessive pronouns (Doležel, 1973). FID was later found in first-person narration as well although under rare circumstances. In this type of texts, as Cohn described with the terms "narrating self" and "experiencing self" (Cohn, 1978, p.167), the relationship between these two positions of narrators "corresponds exactly to the relationship of a narrator to his character in a figural third-person novel: the narrator momentarily identifies with his past self" (Cohn, 1978, p.167). In the study, Cohn also includes a section of "self-narrated monologue", which is devoted to FID in first-person texts (Cohn, 1978). Similarly, Elly Hagenaar points out that a distinction can be drawn between the narrator in two various positions, that is, "at the moment of narration" and "at the moment in the past when he experienced the narrated events" (Hagenaar, 1992, p.16). Due to the fact that this circumstance is not very common in literary works, FID in first-person narration does not occur frequently.

In terms of verb sense, FID combines features of narrator's discourse and character's discourse. In most cases, FID passages employ the form of past tense, however it should be pointed out that, in some circumstances, for example, when the story originally is narrated by past tense, this aspect cannot be used to recognise FID. Additionally, in some languages, such as Chinese, there is no concept of "tense", and thus there does not exist the so-called "past tense", which will be discussed in detail later. Thereby, some alternative verbal feature may provide the same function. Just as Lethcoe indicated, the verb shifts can probably become signals of FID. Such shifts, for instance, may be from preterite to past progressive or to past future, shift to a greater past tense, or sudden shift to an imperative (Lethcoe, 1969). Or, as McHale mentions, some modal auxiliaries which refer to speculation or a supposed obligation or permission, such as "might", "ought to", "should", "must" and so forth, enable us to recognise FID (McHale, 1978). Doležel also points out that these expression to some extent imply "a speaker whose point of view differs from the narrator's" (Doležel, 1973, p.28).

The concept of deixis is important in the field of linguistics and refers to phrases such as "here", "his", "that", "yesterday" and so forth. According to Doležel, deixis has "the function of pointing to the shifting time-space position of the speaking character" (Doležel, 1973, p.29), which just concurs with the situation of the character's discourse, while the narrator's discourse is non-situational. Thus, we can see that in this respect, FID behaves like character's discourse. To explain it more clearly, the following examples will be taken from Lethcoe looking at the difference between FID and DD as well as ID in this category (Lethcoe, 1969, p.7):

DD: He spoke: "I am going to the police this very minute! I will have you arrested! Do you think you can break the law without punishment?"

ID: He said that he was going to the police that very moment. He claimed that he would have him arrested. He asked whether he thought he could break the law without punishment.

FID: He was going to the police this very minute! He would have him arrested! Did he think that he could break the law without punishment?

It can be seen that FID does not shift the space-time perspective from that of the character to that of the narrator but employs the same reference system (that of the character) as direct speech.

In addition, as Bronzwaer and Stanzel point out, combinations of time-denoting adverbs with past-tense verb forms can be considered as striking signals in FID passages (Hagenaar, 1992, p.22), ${ }^{2}$ however, which are impossible to appear in our spoken language. Hegenaar takes an example from a German novel: "But in the morning she had to decorate the tree. Tomorrow was Christmas." In this example, it can be seen that the last sentence "tomorrow was Christmas"

\footnotetext{
${ }^{2}$ The above takes the reference of translation by Elly Hagenaar.
} 
obviously cannot be spoken in oral language normally, with the word "tomorrow" representing the notion of future time against the preterite "was" expressing the past time (Hagenaar, 1992, p.22).

Apart from the three ordinary signals above, some scholars list other signals to recognise FID passage under some special circumstances. In terms of syntactic features, for instance, Lethcoe mentioned several aspects, including elliptical constructions, repetitions, optative constructions, conjunctives and conjunctive adverbs in the initial position as well as the use of "you" for impersonal constructions (Lethcoe, 1969). Moreover, the fact that syntactic features are effective in the emotive function of FID has been widely recognised. In this respect, both Doležel and Bronzwaer made a statement in their studies. For example, Doležel listed several aspects, which includes interjections, exclamatory sentences, optative sentences, and deliberative or rhetorical questions (Doležel, 1973, p.32). Bronzwaer also found several relevant factors, including prolepsis and strings of related words or synonyms (Bronzwaer, 1970, p.49).

Secondly, from a semantic perspective, Doležel specifies two factors, that is, attitudinal semantics and modality. He highlights attitudinal semantics as "the expression of individual attitudes and evaluations relating to the verbalised thoughts, depicted actions, characters, etc.", and defined modality as "that evaluation of the verbal action which attributes to it the quality of reality, unreality, possibility, conditionality, desirability or necessity". Doležel also emphasises that for FID passage the modality is always subjective; that is to say, "the modal status of verbal actions is here controlled by the decision of a speaker, in accordance with the general trends of his subjective semantics" (Doležel, 1979, pp. 35-39). Besides, McHale also pointed out similar semantic devices of modality, for example, some adverbs to convey doubt or certainty, speculation or supposition, such as "maybe", "perhaps", "certainly", "possibly", "probably", and so forth. Additionally, he also mentions "lexical fillers", which "express an ongoing internal or external exchange", such as "of course", "after all”, "anyway", "surely", "so", “yes”, "no" and so on (McHale, 1978, pp.265-269).

Moreover, Lethcoe lists some semantic devices for recognising FID in texts. He provided a relatively comprehensive list for us: intensifiers and emphatic particles, including even, so, just, only, too, such; adverbs and adjectives that intensify ("quite", "awfully", "absolutely", "totally") or that stress absolute or extreme states ("always", "never", "every", "no"); contractions such as "wasn't" and folk proverbs (Lethcoe, 1979, pp.121-129). He also highlights the importance of context, especially regarding semantic discriminative features of FID. In Lethcoe's opinion, for FID passage, "it is usually those elements which contrast the most to the narrator's style in his pure narration which provides reliable indices" (Lethcoe, 1979, p.93).

Thirdly, in addition to syntactic and semantic features, some contextual signals can also be quite useful for us to recognise FID in the texts, for example, the frequent presence of certain verbs. We should notice that some verbs often precede or follow a passage of FID or just intercalate between it. Regarding this, Bronzwaer compares FID with ID, and he argues that FID appears to "differ from indirect speech only in so far that a matrix sentence containing a verb of the 'speak', 'think' or 'feel' class has been deleted". He also points out that "such a verb, or an expression related to it, is still very often present in the context, although not directly related to the free indirect passage by any syntactic link" (Bronzwaer, 1970, p.54), for example, in some verbs expression such as "to recall", "to seem", "to remember", "to feel", "to realise" and so forth, as well as in some expressions with nouns like "reason", "thought", "sense" (Bronzwaer, 1970, p.54). Lethcoe mentions this aspect as well. He proposed that the so-called "preparations" in the context possibly also take the form of a description of gestures or facial expression, although it is most often the description of a character's consciousness that is able to precede the FID passage (Lethcoe, 1979, p.82).

\section{The Historical Transition OF FreE InDiReCT Discourse IN CHINA}

\section{A. Translating FID Passages into Chinese}

Before exploring the development of FID in early Chinese fiction, this section will look at how FID passages in Western literary works were translated into Chinese in early works, thereby investigating the transition of FID in Chinese.

First of all, as mentioned above, typical FID always employs the third-person system in third-person narration, so how about the translations into Chinese? The following is a passage from the novel Ulysses:

Father Conmee stopped three little schoolboys at the corner of Mountjoy square. Yes: they were from Belvedere. The little house: Aha. And were they good boys at school? O. That was very good now. And what was his name? Jack Sohan. [...] And the other little man? His name was Brunny Lynam (Joyce, 2008, p.156).

The translation of the two sentences "And what was his name?" and "His name was Brunny Lynam" from Xiao Qian is: Namo, ta jiao shenme mingzi? (那么, 他叫什么名字?) and Tade mingzi jiao Bulunni Lainamu (他的名字叫布伦 尼·莱纳姆) (Joyce, 1994, p.261). However, for other two sentences "Yes: they were from Belvedere" and “And were they good boys at school?”, the translation becomes: Shide, Beierfudaerde (是的, 贝尔福达尔德) and Doushi haoxuesheng ma? (都是好学生吗?). We can see that the original personal pronoun in English does not exist again in the Chinese translated version; for example, in the latter sentence, the original personal pronoun "they" has been substituted by the adverb dou (都 all), which merely refers to a plural. Thus, as Elly Hegenaar reveals, the necessity of stating the subject of a sentence explicitly seems not as strict as in western languages (Hagenaar, 1992, p.43).

In a word, when it comes to the aspect of grammatical person in FID passages, it is ordinarily maintained in the Chinese translational text, but sometimes also replaced with the indefinite form or eliminated altogether. 
The second point we should consider is the verb tense. As mentioned above, in Chinese there is no exact concept of "tense". There are some words in Chinese which can reflect past tenses, such as guo 过 and le 了, but to be precise, Chinese has “aspect” ( $t a i$ 态) instead of “tense" ( $s h$ 时). The linguist Roman Jacobson once referred to Chinese as “an aspect-dominant language" in which the tense always occupies the secondary position when indicated in the verb phrase. In his study, Jacobson proposed the idea of "shifter", which was defined by him as a verbal category that bears reference to the speech event or its participations, and thus he regarded tense as a shifter, while aspect is a non-shifter (Jacobson, 1971, pp.134-136). Hagenaar further interprets it as well: one might expect to find aspect markers in passage rendering past-tense texts more frequently than in those rendering present-tense texts, but since aspect markers bear no reference to the speech event, the epic preterite involved in FID has no equivalent in Chinese (Hagenaar, 1992, p.44). Overall, we can say that, in terms of the signal of verb tense, there is no equivalent in Chinese translation of FID passage.

Third, as stated before, deixis is another important feature for FID passages, so next we will take a fragment from Mrs. Dalloway as an example to look at how it works in Chinese translation:

Her only gift was knowing people almost by instinct, she thought, walking on. If you put her in a room with someone, up went her back like a cat's; or she purred... what she loved was this, here, now, in front of her; the fat lady in the cab (Woolf, 1925, p.11).

This passage reveals the free thoughts of the female protagonist when she is taking a walk, in which the words like "this", "here" and "now" are deictic demonstratives from the protagonist's point of view. In the Chinese version, this sentence is translated into: Ta shuo xi'ai de jiushi zhege, xianzai, zaizheli (她说喜爱的就是这个, 现在, 在这里) (Woolf, 2001, p.25). As a result, we can see that deictic features are usually maintained in Chinese translational version of FID passage; however, Hagenaar argues, in certain cases, there may exist some differences in usage, especially in the rendering of "this" and "that", and she exemplifies this point with an example from Ulysses (Hagenaar, 1992, pp.45-46). The sentence “O, that was a nice name to have" was translated into Chinese as: Hei, zhege mingzi qude tinghao (嘿, 这 个名字取得挺好), so it can be seen that the deictic word “that” in the original sentence is replaced with zhege [this 这 个] rather than nage [that 那个] (Joyce, 1994, p.302).

Overall, except the verb tense, other syntactic features of FID passages in western literary works are rendered into Chinese. As for semantic characteristics, according to Hagenaar, it is difficult to render directly into Chinese, on account of stylistic or idiomatic considerations, while contextual signals are usually easily rendered in the Chinese version, but they are sometimes eliminated on account of idiomatic requirements (Hagenaar, 1992, p.47).

\section{B. FID in Chinese Literature}

The appearance of FID as an independent literary technique in Chinese fiction is quite early, and it can be traced even further back than the notion of stream of consciousness. Some literary works written before the Republican era have been studied with a view to narrative method. For example, Michael Egan looked at FID in the novel Hen Hai (Sea of woe) by Wu Woyao (1866-1910) in 1906. Describing the application of FID as an intermediary stage in its development, he remarks: in Hen Hai, the use of represented discourse "is not yet fully developed or mastered, but there are indications of the blurring of lines between the narrator's text and the character's text" (Egan, 1980, pp.170-172). So, Egan highlights the function of FID in the psychological characterization (Egan, 1980). It should be noted that Egan uses the term of "represented discourse" rather than "free indirect discourse" which was actually based on the study of Doležel. In addition, he emphasises the great importance of the change of the protagonist's mentality in the story, especially comparing with earlier novels. Apart from Egan, other scholars have also mentioned the importance of this novel on the development of narrative devices in Chinese literature. For example, although Henry Zhao does not mention FID in this novel, he regards Sea of Woe as the first novel employing the extensive psychological description in Chinese literature (Zhao, 1987).

Additionally, although some of the previous studies reveal that FID was borrowed from western fiction since the appearance of Chinese translations of some western fiction in nineteenth century, ${ }^{3}$ through the review of FID's early history in Chinese literary works, it is convincing that actually this sort of the so-called "new" narrative technique was not totally introduced from western fiction. Besides, as Doleželová reveals, "foreign fiction cannot be directly associated with the artistic advances of the late Qing fiction” (Doleželová, 1988, pp.12-13). At that time, most translations were actually not professional translations, often skipping many "obscure" points for them; rather, it might be seen as more similar to paraphrase. As a result, we may conclude that FID can be considered in Chinese local contexts as "an internal development" (Hagenaar, 1992, p.41).

During the May Fourth era, diversified narrative techniques greatly developed in Chinese fiction, and FID began to frequently appear in the writings, and some western scholars have focused on these works as well. For example, the Czech sinologist, Jaroslav Průšek, analysed the narrative methods used by Mao Dun (1896-1981) in his writings, and he mentioned Mao Dun's preference for subjective narration (Průšek, 1980, p.126). In his opinion, Mao Dun reproduced

\footnotetext{
${ }^{3}$ For example, in the study about the translation works of Kafka in Chinese, Meng argues that FID had been introduced through the translation of Dicken's works (Meng, 1986, p.164).

${ }^{4}$ Here, I think that the saying taken from Hagenaar can be applied well to depict it.
} 
interior monologue through FID. Furthermore, Průšek specifically took a passage from Ziye (Midnight, 1933) as an example to interpret the usage and function of FID in his works. In fact, Průšek used the term "semi-direct speech" rather than using FID directly in his study. In his opinion, Mao Dun actually focused more on collective issues with broader, objective importance rather than on individuality. In this respect, FID plays a significant role on dramatising the presentation (Prǔšek, 1980, p.126). In addition, Roy Chan exemplifies the usage of FID in Mao Dun's novella Huanmie (Disillusionment, 1927). Chan points out that the author's intense focalisation of the narrative through the female protagonist's psyche and body is always aided by FID (Chan, 2017).

FID in Lao She's (1899-1966) writing has been studied as well. For instance, Richard So emphasises Lao She's skilled use of FID, which "caused hundreds of thousands of American readers to mistake the voice of Xiangzi, the character, for the voice of Lao She, the author" in Luotuo Xiangzi (Camel Xiangzi, 1936) (So, 2016, p.205). Lydia Liu recognises the free indirect speech in this novella as well (Liu, 1995).

Apart from being an independent literary technique in modern fiction, FID as an important narrative technique to present SOC style has been widely recognised in the writings of the 1930s's New Perceptionist group including Liu $\mathrm{Na}$ 'ou and Shi Zhecun, and it has become a great interest to some scholars. For example, in Shanghai Modern, Leo Oufan Lee mentions that this kind of narrative device was widely used by Shi Zhecun in his short story collection Shan nüren xingpin (Exemplary conduct of virtuous women, 1933) to depict a series of psychological portraits of modern Chinese women (Lee, 1999, p.167). As Lee points out, it is the lack of rigid tense system, pure tense markers, and any strict rules governing the agreement between subject and predict that makes it possible for FID to be used more flexibly in modern Chinese literature, and Shi's writing can be considered a typical example (Lee, 1999).

In addition to the writers mentioned above, many modern women writers also practised free indirect discourse in their creative writing, but their use of this form has been largely neglected and no scholarship of note produced on the topic.

\section{CONCLUSION}

As a discourse presentation pattern of third-person narration, free indirect discourse is often employed as a common narrative strategy to present characters' consciousness in literary works. Given its ambiguous link with both the narrator's and character's discourse, we may feel confused about how to distinguish FID from other discourse when reading a text. This paper firstly introduced the basic definition of this notion, and interpreted several signals which can help to distinguish FID passages in the text. In addition, this paper examined how FID passages in Western literary works were translated into Chinese in early works, and revealed the development of FID in early Chinese fiction, investigating the transition of FID in Chinese. Except the verb tense, other syntactic features of FID passages in western literary works are rendered into Chinese. As for semantic characteristics, it is difficult to render directly into Chinese. Moreover, it can be found that the appearance of FID as an independent literary technique in Chinese fiction is quite early, and it can be traced even further back than the notion of stream of consciousness.

\section{REFERENCES}

[1] Bowling, Lawrence. (1950). What is the Stream of Consciousness Technique?. PMLA 65, no. 4: 333-345.

[2] Bronzwaer, W.J.M. (1970). Tense in the Novel: An Investigation of Some Potentialities of Linguistic Criticism. Groningen: Wolters-Noordhoff.

[3] Chan, Roy Bing. (2017). The Edge of Knowing: Dreams, History, and Realism in Modern Chinese Literature. Seattle: University of Washington Press.

[4] Chatman, Seymour Benjamin. (1980). Story and Discourse: Narrative Structure in Fiction and Film. New York: Cornell University Press.

[5] Cohn, Dorrit. (1966). Narrated Monologue: Definition of a Fictional Style. Comparative Literature 18: 97-112.

[6] Cohn, Dorrit. (1978). Transparent Minds: Narrative Modes for Presenting Consciousness in Fiction. Princeton: Princeton University Press.

[7] Dillon, George L. and Frederick Kirchhoff. (1976). On the Form and Function of Free Indirect Style. PTL: A Journal for Descriptive Poetics and Theory of Literature 1: 431-440.

[8] Doležel, Lubomir. (1973). Narrative Modes in Czech Literature. Toronto: University of Toronto Press.

[9] Doleželová-Velingerová, Milena. (1988). Understanding Chinese Fiction 1900-1949. Selective Guide to Chinese Literature 1: 3-45.

[10] Egan, Michael. (1980). Characterisation in Sea of Woe. In The Chinese Novel at the Turn of the Century. Edited by Milena Doleželová-Velingerová. Toronto: University of Toronto Press.

[11] Genette, Gérard. (1983). Narrative Discourse: An Essay in Method. New York: Cornell University Press.

[12] Greimas, Algirdas Julien. (1983). Structural Semantics: An Attempt at a Method. Translated by Daniele McDowell, Ronald Schleifer, and Alan Velie. Lincoln: University of Nebraska Press.

[13] Hagenaar, Elly. (1992). Stream of Consciousness and Free Indirect Discourse in Modern Chinese Literature. Centre of NonWestern Studies. Leiden: Leiden University.

[14] Hernadi, Paul. (1972). Dual Perspectives: Free Indirect Discourse and Related Techniques. Comparative Literature 24, no.1: $32-43$.

[15] Joyce, James. (2008). Ulysses. Oxford: Oxford University Press.

[16] Joyce, James. (1994). Youlixisi [Ulysses]. Translated by Xiao Qian and Wen Jieruo. Beijing: Yilin chubanshe. 
[17] Lee, Leo Ou-fan. (1999). Shanghai Modern: The Flowering of a New Urban Culture in China, 1930-1945. Cambridge: Harvard University Press.

[18] Leech, Geoffrey and Mick Short. (2007). Style in Fiction: A Linguistic Introduction to English Fictional Prose. London: Pearson Education.

[19] Lethcoe, Ronald. (1969). Narrated Speech and Consciousness. PhD thesis, University of Wisconsin.

[20] Li Xuemei. (2007). Lun ziyou jianjie yinyu zai hong longmeng neixin dubai zhongde zuoyong [On the function of FID in interior monologues of Hong lonmeng]. Hunan nongye daxue xuebao (shehui kexue ban) vol.8, no.6.

[21] Liu, Lydia He. (1995). Translingual Practice: Literature, National Culture, and Translated Modernity--China, 1900-1937. Palo Alto: Stanford University Press.

[22] Lu Hsun. (2000). A Brief History of Chinese Fiction. London: The Minerva Group, Inc.

[23] Meng Weiyan. (1986). Kafka and China. München: Iudicium Verlag.

[24] McHale, Brian. (1978). Free Indirect Discourse: A Survey of Recent Accounts. PTL: A Journal for Descriptive Poetics and Theory of Literature 3: 249-287.

[25] Prince, Gerald. (2003). A Dictionary of Narratology. Lincoln: University of Nebraska Press.

[26] Scholes, Robert and Robert Kellogg. (1966). The Nature of Narrative. Oxford: Oxford University Press.

[27] Shen Dan. (1991). "Dui ziyou jianjie yinyu gongneng de chongxin pingjia" [Re-evaluation on the function of free indirect discourse]. Waiyu jiaoxue yи уапjiu, no.2: 11-17.

[28] Shen Dan. (2014). Xushixue lilun tanze [Exploration on narratological theory]. Taipei: Xiuwei chuban.

[29] So, Richard Jean. (2016). Transpacific Community: America, China, and the Rise and Fall of a Global Cultural Network. New York: Columbia University Press.

[30] Wang Li. (1955). Zhongguo yufa lilun [Theory of Chinese grammar]. Beijing: Zhonghua shuju.

[31] Woolf, Virginia. (2014). A Room of One's Own. In Modern Criticism and Theory: A Reader. Edited by Nigel Wood and David Lodge. London: Routledge.

[32] Woolf, Virginia. (2001). Daluowei furen [Mrs. Dalloway]. Translated by Wang Jiaixiang. Nanjing: Yilin chubanshe.

[33] Woolf, Virginia. (1925). Mrs. Dalloway. New York: Harcourt, Inc.

[34] Woolf, Virginia. (2016). The Mark on The Wall. London: Fb \&C Limited.

[35] Yuan Kejia. (2003). Yishiliu Wenxue [Stream-of-consciousness literature]. In Oumei xiandai wenxuepai wenxue gailun [On European and American literature of modernism]. Nanning: Guangxi shifan daxue chubanshe.

[36] Zhao, Henry Y. H. (1995). The Uneasy Narrator: Chinese Fiction from the Traditional to the Modern. Oxford: Oxford University Press.

[37] Zhang, Yingjin. (1998). China in a Polycentric World: Essays in Chinese Comparative Literature. Palo Alto: Stanford University Press.

[38] Zhao, Henry Y. H. (1995). The Uneasy Narrator: Chinese Fiction from the Traditional to the Modern. Oxford: Oxford University Press.

[39] Zhao Yiheng. (1987). Xiaoshuo xushu zhongde zhuanshuyu [Reporting mode in narrative in fiction]. Wenyi yanjiu, no.5: $78-87$.

Yixin Liu was born in Shanxi, China. She received her doctorate degree in the University of Edinburgh in 2021. Her research focuses on Republican Chinese literature and culture. 